Impresiones y retos para la construcción de paz desde el Comité de Integración del Macizo Colombiano (CIMA): fragmento de entrevista con César William Díaz Morales, líder social del proceso campesino caucano 


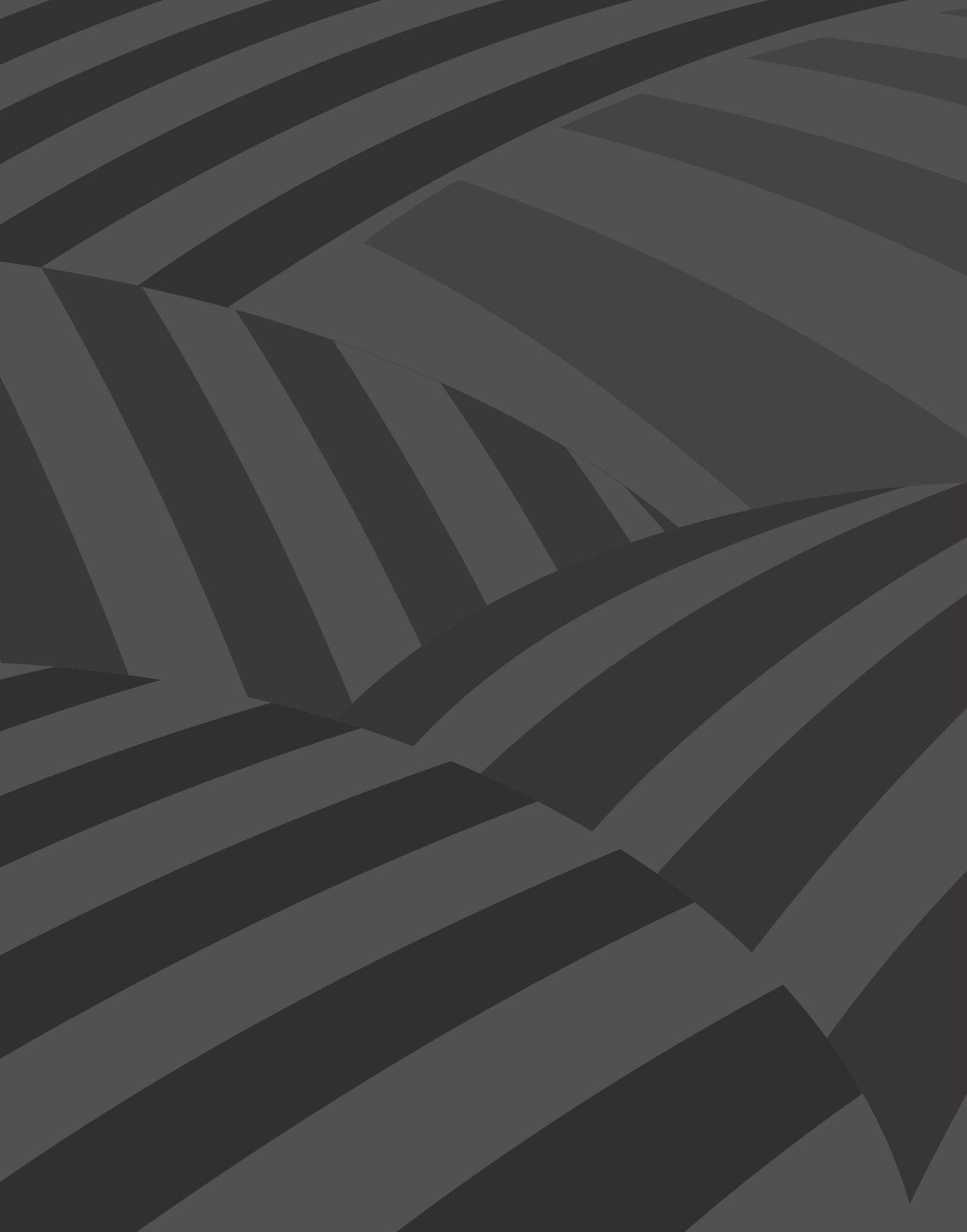




\section{Impresiones y retos para la construcción de paz desde el Comité de Integración del Macizo Colombiano (CIMA): fragmento de entrevista con César William Díaz Morales, líder social del proceso campesino caucano}

Por Edilberto Vergara Argüello*

Resumen: El siguiente fragmento hace parte de la entrevista con un líder social campesino del departamento del Cauca, y pretende exponer algunas reflexiones frente al Acuerdos de Paz, firmado entre el Estado Colombiano y las Fuerzas Armadas Revolucionarias de Colombia FARC-EP. Se abordan temas sobre Derechos Humanos, retos y propuestas sobre construcción de paz desde la organización campesina, Comité de Integración del Macizo Colombiano CIMA, en el departamento del Cauca, Colombia, entre otros.

Palabras clave: implementación Acuerdos de Paz, Derechos Humanos, construcción de Paz, Comité de Integración del Macizo Colombiano-CIMA, campesino.

\section{Perceptions and Challenges for Peace-building from the Perspective of the Integration Committee of the Colombian Massif (CIMA). Fragment of an Interview with a Social Leader of the Peasant Movement in Cauca (Colombia)}

Abstract: The following fragment of an interview with a peasant social leader from the department of Cauca aims to present reflections on the process of implementation of the Peace Agreements signed between the Colombian State and the Fuerzas Armadas Revolucionarias de Colombia FARCEP (Revolutionary Armed Forces of Colombia). Human Rights, challenges and proposals on peacebuilding are addressed from the perspective of the peasant organization Comité de Integración del Macizo Colombiano CIMA (Integration Committee of the Colombian Massif) in the department of Cauca, Colombia.

Keywords: Peace Agreements, Humans Rights, peacebuilding, peasants.

* Antropólogo. edilberto.vergara@javerianacali.edu.co 
Cómo citar este artículo: Vergara Argüello, Edilberto (2018). Impresiones y retos para la construcción de paz desde el Comité de Integración del Macizo Colombiano (CIMA): fragmento de entrevista con César William Díaz Morales, líder social del proceso campesino caucano. Revista Controversia, 210, 245-260.

Fecha de recepción: 20 de enero de 2018

Fecha de aprobación: 25 de abril de 2018

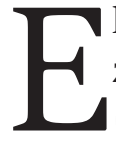

1 Acuerdo de Paz firmado entre el Estado colombiano y las Fuerzas Armadas Revolucionarias de Colombia - Ejército del Pueblo (FARC-EP) fue el resultado de un largo proceso de debate entre las partes, con altibajos y momentos de ruptura inevitables, pero que al final logró, bajo el discurso de la paz, la terminación de un conflicto armado que desangró al país por más de 50 años.

Para las organizaciones sociales, la finalización del conflicto armado con las FARC-EP y los Acuerdos para la implementación del cese al fuego abrieron paso a nuevas posibilidades para avanzar hacia la dignificación de las condiciones de vida de algunos de los sectores rurales más golpeados por el mismo conflicto y por el abandono del Estado colombiano.

Sin embargo, la implementación de los Acuerdos ha generado múltiples debates en distintas esferas a nivel nacional, en relación principalmente a los verdaderos alcances de los mismos, a las múltiples reformas que ha surtido su aprobación, y a las discusiones acerca de si sus propuestas responden a alternativas novedosas, principalmente frente a las necesidades de las áreas rurales, o si por el contrario solicitan nuevamente una serie de derechos y demandas ya consignadas en la Constitución Política del 91, y puntualmente, en las diferentes leyes ya en curso a nivel nacional —en relación principalmente a los puntos relacionados con la Reforma Rural Integral-.

Desde lo local, estos debates han sido protagonizados por distintas organizaciones sociales, quienes desde su quehacer en los territorios han vivenciado cada uno de los programas formulados a nivel nacional, 
para el cumplimiento de los Acuerdos, pero además, sumado a esto, han vivido la reconfiguración del control territorial por parte de diversos actores.

De allí que su análisis sobre la implementación resulte fundamental, en tanto permite escuchar las voces de aquellos que viven el fin del conflicto armado desde la letra menuda de un acuerdo de paz, y con la incertidumbre frente al juego político del Gobierno de turno.

En este sentido, las ideas que se presentan a continuación son parte de una conversación sostenida con integrantes de una organización regional que tiene incidencia en los departamentos del Cauca y Nariño, y que ha aportado en la construcción de alternativas para el mejoramiento de las condiciones de vida de las comunidades en el campo colombiano: el Comité de Integración del Macizo Colombiano (CIMA).

El Comité de Integración es una organización social comunitaria que surge en los años ochenta y noventa en defensa del Macizo colombiano, desde el cuidado, la protección ambiental y las prácticas agroecológicas que permitan la construcción de condiciones de vida digna para las comunidades del suroccidente asentadas en el Macizo. La defensa y lucha que ha adelantado el CIMA ha sido un motor para las reivindicaciones del sector rural campesino, así como para otros movimientos sociales. Desde este proceso de construcción social colectiva se han forjado alianzas con organizaciones estudiantiles, indígenas, afros y sindicales. Así mismo, fue un actor importante en la construcción de la Minga Social y Comunitaria, en el Congreso de los Pueblos, y actualmente participa en escenarios nacionales como miembro activo del Coordinador Nacional Agrario y de la Cumbre Agraria, Campesina, Étnica y Popular.

Como ya fue dicho, el CIMA tiene incidencia en los departamentos de Nariño y Cauca. En el Cauca hace presencia en los municipios de Popayán, Sotará, Timbío, El Tambo, Rosas, La Sierra, Bolívar, Almaguer, El Rosal, San Sebastián, Santa Rosa, Patía, Sucre, Mercaderes, Florencia, 
Balboa y Argelia. A nivel regional incide a través de propuestas de desarrollo, como la Reserva de la Biósfera del territorio del Macizo colombiano, de ordenamiento territorial, como las Zonas de Reserva Campesina, los corredores interculturales de vida digna y los Territorios Agroalimentarios, en los planes de vida y en la participación local comunitaria en distintos niveles, entre otros.

El Cauca ha sido uno de los departamentos más afectados por el conflicto social y armado en Colombia. Los alarmantes hechos de violación de derechos humanos incluyen intimidaciones, amenazas y asesinatos; igualmente, el departamento ha tenido presencia de grupos al margen de la ley, sumado a negocios de narcotráfico y control territorial, y un alto grado de conflictos territoriales. En el marco del proceso de paz en el Cauca se instalaron dos Zonas Veredales Transitorias de Normalización, una en Caldono y otra en Buenos Aires, mientras que en el proceso de implementación se ha dado paso a la instalación del Programa de Desarrollo con Enfoque Territorial (PDET) ${ }^{1}$ del Alto Patía y Norte del Cauca, y se avanza en el proceso de implementación del Programa Nacional Integral de Sustitución de Cultivos Ilícitos (PNIS). En medio de esta complejidad de factores están las organizaciones sociales y comunitarias, con sus propuestas de vida y convivencia en los territorios, para atender las necesidades y avanzar hacia la paz desde los territorios.

Este texto presenta un fragmento de una entrevista realizada a César William Díaz Morales, vocero de la organización CIMA-CNA en las mesas campesinas de interlocución con el Gobierno nacional: Mesa Campesina Cauca CIMA-CNA/PUPSOC-FENSUAGRO y Mesa de Negociación de la Cumbre Agraria, Campesina, Étnica y Popular.

La entrevista se abordó desde tres elementos centrales, donde se destacan las reflexiones sobre el proceso de implementación de los acuerdos de paz, en segundo lugar se pregunta por la situación de derechos

1 Creados a través del Decreto 893 del 28 de mayo de 2017. 
humanos en el territorio, y finalmente se mencionan retos y propuestas desde el Cima para la construcción de paz. De esta manera, el dialogo en Voz desde la Base con los sectores rurales campesinos es clave para conocer cómo ha sido el proceso de la implementación de los acuerdos de paz, cuáles son las falencias y cuáles las alternativas para alcanzar la dignificación desde y para el campo colombiano.

Edilberto: ¿Cómo ha sido el proceso de implementación de los acuerdos de paz?

César William: El Comité de Integración del Macizo Colombiano desde siempre ha planteado la necesidad de la construcción de paz desde una concepción comunitaria. Y hemos visto en las negociaciones que se establecieron o que se hicieron públicas entre el Gobierno y las insurgencias una oportunidad. Sin embargo, toda la vida hemos planteado que la paz debe ser una construcción desde las comunidades, también hemos dicho que es la búsqueda de la solución política de los conflictos, tanto armados como sociales.

Concebimos que la paz no es simplemente un armisticio entre grupos armados -en este caso entre la fuerza pública por parte de la institucionalidad, o la orientación que las élites le dan en la administración del Estado, y los grupos insurgentes que tienen propósitos políticos-, sino que la construcción de la paz es para nosotros un derecho como tal, que está consagrado incluso en las normas, no solo nacionales sino internacionales; la paz es la realización de los derechos. O sea, no puede haber una condición de armonía, de convivencia y otros apelativos que le dan a la paz si no hay una realización de los derechos y una realización de los intereses de las comunidades y de todos los actores en una sociedad.

Nosotros reconocemos que al Gobierno no le interesa y no le agradan los puntos 1 y 4 del Acuerdo, porque nosotros lo exigimos incluso desde la 
Cumbre y desde las mesas y los espacios propios: la solución estructural al tema de los cultivos en el país es el desarrollo del campo, y en particular de las economías propias. Pero la economía campesina nunca ha tenido apoyo, la economía campesina se ha hecho contra corriente, contra tratados de comercio, contra leyes que prohíben las semillas propias, contra créditos caros que no dan garantías ni cubren riesgos en la producción rural, cambios de clima, de inundaciones, de pérdidas de cosechas, nada de eso nos han cubierto. Sin embargo, se persiste en la economía campesina, en la agricultura, en el desarrollo agropecuario propio.

A pesar de no tener los apoyos, casi que el Acuerdo de Paz se vuelve en otra herramienta para nosotros del sueño de cambiar esa realidad, y acceder a la tierra, acceder al reconocimiento de derechos, acceder a políticas públicas. Sin embargo, se está viendo que los acuerdos finalmente se vuelven funcionales a la promoción de ciertos cultivos, a la promoción de ciertos créditos, al despojo de la riqueza, ya no solo de la tierra, sino de la mano de obra y del saber campesino en beneficio de los agroindustriales y los agroexportadores, que son quienes están acumulando la riqueza, y no se resuelven los problemas estructurales, que son los que siempre hemos alegado.

Edilberto: ¿Cómo avanza la implementación de los Acuerdos Paz en el Cauca y cómo ha sido el proceso de transformación de la institucionalidad para responder este reto?

César William: Primero, decir que el desarrollo de la institucionalidad es lento, y hay maneras de hacer disfuncional una institución: o ponerle mucho trabajo, o quitarle presupuesto, o ambas. Eso es lo que ha venido pasando, el PNIS en el Cauca tiene 4 funcionarios para atender 35 municipios, y dicen: "no damos abasto". Finalmente priorizamos y se concentraron en 5. ¿Pero qué pasó con la expectativa de los otros 30? ¿Qué pasó con la construcción comunitaria y social de los otros 30 ? 
En el Cauca hicimos el balance, y de los municipios PDET que estaban previstos y que tenían cultivos, eran la mayoría de los 17 que estaban en el PDET de norte del Cauca y Alto Patía², —que debería llamarse Alto Cauca y Alto Patía-, mientras que en el Programa de la Costa Pacífica el departamento del Cauca tiene 20 municipios. Ampliamos el tema de 35 a 42, por lo que aumentaron y casi se duplica el número de municipios afectado por conflictos, afectados por violencia, por cultivos, por pobreza, por marginalidad, por falta de presencia de la institucionalidad.

Entonces, ¿qué quiere decir eso? Que en esa radiografía está reflejado todo el país: en muchas partes en donde la insurgencia hizo presencia, pero incluso donde no hicieron presencia, pero se presentan todas estas condiciones de violencia por otros actores y por la misma fuerza pública, hay un acuerdo político, y no pueden ser todos, hay que priorizar y son 10 años. En cambio el PNIS solo tenía 3 años: al PNIS se le acaba su cuarto de hora el año entrante en mayo, y ya no logramos mayor cosa en lo de sustitución, por lo menos por la vía concertada, ahora toca por la vía de la movilización y toca la resistencia ante la erradicación forzosa.

Un ejemplo: la articulación interinstitucional, la coordinación interinstitucional, la nueva institucionalidad creada con las normas derivadas de los acuerdos y otras, nos dieron la razón. Había que integrar el PNIS, por la debilidad institucional del programa en el país, y en el Cauca al PDET, que tenía más fortaleza. Claro, era por municipios, tenían 34 profesionales, en vez de 4 del otro [PNIS], pero no se compara con la fuerza pública, que tiene 5.500 efectivos para erradicar, para una sola acción. En cambio, el PDET tiene 34 profesionales para intervenir en los municipios, hay unas metodologías para establecer estrategias de participación, para resolver temas, como la relación con la Agencia

2 Los municipios que conforman el pdet Alto Patía y norte del Cauca son, en Cauca: Argelia, Balboa, Buenos Aires, Cajibío, Caldono, Caloto, Corinto, El Tambo, Jambaló, Mercaderes, Miranda, Morales, Patía, Piendamó, Santander de Quilichao, Suárez, Toribío; en Nariño: Cumbitara, Rosario, Leiva, Los Andes, Policarpa; en el Valle: Florida y Pradera. 
Nacional de Tierras (ANT) ${ }^{3}$, porque el Estado dice que no invierte, póngale cuidado a esta cosa, en el caso de los PNIS y de los PDET, no invierten en zonas que no tengan los títulos claros, que no haya formalización de la propiedad por el proceso del Ministerio de Agricultura y de la Agencia de Tierras.

En el caso del Cauca, la fase de construcción de PDET quedó en el nivel municipal: apenas se iban a empezar a validar en las asambleas con los grupos motores y los actores estratégicos esas iniciativas, porque fue una exigencia nuestra en la metodología, y casualmente sale una amenaza, involucrando a los funcionarios y actores públicos del Programa, a las organizaciones sociales y a los líderes de los espacios de concertación y negociación como enemigos del país, porque somos amigos de la paz. Es la contradicción: ahí queda claro cuáles son los intereses que hay.

Ahora bien, la tendencia del Gobierno actual, que por lo menos, desde el punto de vista político, ha reculado, diciendo que va a mantener el diálogo social, es una expectativa. Por supuestos políticos, en un mes de entrada del Gobierno no va a decir que va a negar los acuerdos, y ese es un debate que le dimos al gobernador del Cauca. Le dijimos señor gobernador, el gobierno departamental tiene 28 mesas territoriales con alcance nacional, si el Gobierno nacional niega esos compromisos, si el Gobierno dice que va a negar el diálogo social a usted se le revientan 28 mesas, y al Gobierno nacional le toca venir a atender 28 conflictos de distinta índole por todos los temas.

3 Agencia Nacional de Tierras (ANT). Creada a partir del Decreto 2363 del 7 de diciembre de 2015, es la entidad encargada de ejecutar las políticas formuladas por el Ministerio de Agricultura y Desarrollo Rural sobre el ordenamiento social de la propiedad rural. También tiene como función garantizar el acceso a la tierra para los campesinos y formalizar la propiedad, administrar y disponer de los predios rurales de propiedad de la nación y velar por el adecuado uso de la tierra, relacionado con la función social y ambiental de la misma. 
Edilberto: ¿Cómo se ve la situación de derechos humanos en el Cauca?

César William: Nosotros decimos que lo del acuerdo de la insurgencia con las FARC y lo que se viene con el ELN, todavía en el caso del Cauca, nosotros podemos hablar de pos acuerdo, pero no de posconflicto. La razón central: los territorios están en disputa, y están en disputa para insertarlos al modelo económico o hegemónico extractivista. Por cualquier vía, por la vía de la inversión, de la disuasión, de la cooptación, o por la vía de la fuerza de eliminar a los opositores al modelo, eliminar los resistentes, para implementarlo por la vía legal o por la vía ilegal. Y creo que el análisis toca hacerlo más desde la geoestrategia. ¿Qué significa el Cauca en el país? ¿Qué significa el Cauca como territorio, dotado de una riqueza natural que hoy está siendo vista por los ojos codiciosos de los inversionistas nacionales y extranjeros? El Cauca tiene la única zona de confluencia intertropical que le queda al país, que es la conexión del Pacífico, de los Andes y del Piedemonte amazónico. Ahí hay un encuentro de regulación climática, así como recursos naturales, y eso nos da ciertas connotaciones en la región, y al Macizo en particular. Pero también, el Cauca tiene costa pacífica, y digamos que la trashumancia del mercado de la coca de tiempo atrás, pues llegó por la frontera o se hizo a la frontera del Putumayo, el sur del país, algo de la Amazonía, por la conexión de los cultivos del Piedemonte amazónico peruano-boliviano.

Ahora bien, desde las comunidades hay unas acciones de denuncia y resistencia que no están siendo reconocidas, y finalmente lo que nos está afectando se mantiene, uno diría se recrudece y se acentúa. Pero se aumentan los niveles de victimización, con una debilidad: por ejemplo, no tenemos hoy a quien exigirle que cumpla el DIH, a un grupo delincuencial, a un grupo paramilitar usted no le puede pedir que cumpla el DIH, porque no es una fuerza política ni le interesa, digamos que su objetivo político obedece a garantizar la rentabilidad de una inversión y no le interesa quedar bien con nadie, no le interesa hacer acuerdo con el Estado; es más, uno diría que los niveles de corrupción del Estado 
y la fuerza pública, y en los niveles de convivencia o de complicidad, incluso se ve el uso de una estrategia de encubierta, pues les interesa de que eso esté así.

Porque en una zona militarizada que aparezcan amenazas, muertes, retenes, presencia de actores armados supuestamente no existentes con toda la fuerza pública de ahí, o hay corrupción, o hay anuencia, o hay una estrategia deliberada. A uno le quedan todas esas dudas, y podría uno tener muchos indicios para argumentarlas mientras no haya un pronunciamiento claro de las autoridades, diciendo que eso no es así y mostrando el cambio en la realidad, no solo el cambio en el comportamiento de la fuerza pública, sino en la realidad de los territorios.

Edilberto: ¿Cuáles son los retos hacia la construcción de la paz y la solución de los conflictos?

César William: Nosotros tenemos un reto, y es que se nos reconozca a las organizaciones, a las comunidades, y en particular a los campesinos en nuestros derechos, pero sobre todo en el que somos constructores de paz. Así como dicen las mujeres: “que la paz no nos cueste la vida, ni una menos”, promovemos nuestras agendas de paz, nuestras iniciativas de paz, que han sido desde siempre. Nosotros decimos: la necesidad ha sido madre de las organizaciones, y las organizaciones responden a esas necesidades con soluciones, no solamente requiriendo al Estado, haciendo exigibilidades, sino también con propuestas claras. Entonces seguimos en la labor de incidir para que se dé el reconocimiento de nuestras iniciativas y de nuestras propuestas y que sean tenidas en cuenta para el Gobierno.

De la misma manera, está la Agenda de Paz Joven del Cauca ${ }^{4}$, donde Macizo Joven tiene un liderazgo, y se está trascendiendo a una política

4 Es un escenario de participación e interlocución de los jóvenes del Cauca. Este proceso inició en el año 2008, y ha logrado construir lineamientos para el reconoci- 
pública de juventud departamental, haciendo interlocución en los municipios para que esa política de juventud nacional tenga reflejo en los municipios a través de plataformas juveniles locales donde tenemos incidencia, ganando espacios de participación. Con esto se busca reconocer otros niveles de participación de los jóvenes, excluyéndolos del conflicto armado, del servicio militar obligatorio, del reclutamiento de fuerzas no institucionales o ilegales. El servicio social por parte de los jóvenes es clave para que desarrollen su iniciativa y su capacidad desde la escolaridad, pero también desde lo comunitario.

La Agenda de Paz de las Mujeres del Cauca es otro escenario que tiene un tema fuerte de incidencia en la política pública, que parte del reconocimiento del trabajo de la Economía del Cuidado que debe ser reconocido por el Estado. Hoy incide un poco en la construcción de la política de la mujer rural, tratando de que ese tema tenga unos componentes mínimos hacia la mujer rural, como un salario mínimo, una pensión, para garantizar que haya mano de obra, cultura campesina, familia campesina, semillas campesinas, pero también el acceso a la tierra, para que la mujer tenga mejor condición de producción y de vida en las distintas líneas de producción que el campesinado tiene, sobre todo en la producción de alimentos. Se pretende que el saber campesino en la mujer sea reconocido por el Estado y se le dé reconocimiento económico, además del reconocimiento social y político, cultural y político. Y por supuesto, el reconocimiento de la participación de la mujer en la vida política y social.

Entonces están esas agendas, más nuestras apuestas agroambientales, la construcción de la territorialidad campesina, el reconocimiento de los derechos del campesinado, en el caso de nosotros de la identidad y la cultura maciceña, el territorio del Macizo, y que sean reconocidas esas apuestas. Eso es nuestra agenda y plataforma política estratégica,

miento de los derechos de los jóvenes y la participación social a diferentes niveles. 
pues se la juega en el escenario de construcción de paz y en la participación, en los diálogos y en lo que haya que hacer.

Edilberto: ¿Las comunidades están preparadas para la paz?

César William: Nosotros creemos que sí, siempre hemos sido gestores de paz y tenemos propuestas de paz desde nuestros intereses, pero también hemos construido con otros. Por ejemplo, la propuesta campesina de interculturalidad como agenda de desarrollo propio que hemos promovido en el caso del Cauca y en ocho municipios, de hablar de la Reserva de la Biósfera del territorio Macizo colombiano, así como una agenda de desarrollo regional, el gran macizo de siete departamentos, no solo del Cauca sino de Nariño, Putumayo, Caquetá, Huila, Tolima, Valle, como gran Eco-Región, sigue siendo parte de eso: brindarle condiciones de estabilidad a la vida, no al negocio solamente, sino a la vida en el territorio y en el país. Esto hace parte de nuestra fuerza. Sumado a esto, en el caso de otros actores, incluso antagónicos, nosotros hemos abierto escenarios como el Espacio Regional de Paz del Cauca, donde hemos planteado los diferentes diálogos caucanos, donde hemos planteado diálogos difíciles.

Edilberto: ¿Los actores económicos, los actores productivos y militares están preparados para la paz?

César William: Yo digo que no, están cerrados a un interés mezquino, que es el de acumulación y que no tiene ningún precepto ético de respeto a la vida, a la diferencia, para poder acumular. Entonces, están mutando de inversiones legales e ilegales para mantener su tasa de ganancia. El capital visto de esa manera es inhumano y va contra la vida, siempre ha sido un proyecto muerto, extractor y eliminador de la diferencia.

Edilberto: Finalmente, el mapa político actual y las recientes coyunturas electorales nos han mostrado que las regiones periféricas y marginales 
se están pronunciando en aras de un cambio en el modelo, ¿qué piensa de esto?

César William: Somos la gente afectada por el conflicto; pero sobre todo las gentes afectadas por la marginalidad. Yo diría que hay que trascender en el concepto: somos víctimas de la idea del desarrollo de unos cuantos, que están sacrificando a la humanidad del planeta para sus intereses mezquinos, no están mirando que finalmente han sacrificado tantas vidas con la pobreza y el hambre, que van a terminar eliminándose ellos mismos.

La apuesta por la vida debe ser superior al interés económico y mezquino, no es que no reconozcamos que puede haber intereses económicos, pero debe moderarse si es que estamos en aras de plantear una condición de convivencia. Mientras no podemos nosotros tener en los territorios las condiciones solidarias, que van camino a construir relaciones de solidaridad, relaciones de iguales y no de unos superiores a los otros, ellos están ahí como grupo superior, como grupo de iluminados, de sabedores. Los detentadores del poder que pueden hacer con el resto lo que quieran.

Si ellos tuvieran una propuesta humanista, ese saber, esa tecnología, ese poder debería ser usado para beneficio de la humanidad, no para seguir estableciendo, decimos nosotros, las dos enfermedades humanas más graves: la enfermedad del tener y la enfermedad del poder. Esas dos enfermedades, al hacerse excluyentes, no ven al otro como igual, ven al otro como el competidor al que hay que derrotar, y no importa cómo. Los grandes empresarios compiten entre ellos viendo a ver quien domina al otro, a quien se da el gusto de derrotarlo y hacerlo quebrar y comprarle la empresa: monopolizar. Pero también en el territorio se ve, en la lógica de a quién excluyo, a quién elimino porque se opone a mi interés; pero nunca se va a saciar el tener, que también es un criterio de humanidad. El ser humano no debería pensar en tener más allá de lo que pueda administrar: ya cuando necesita a otro para administrar su 
felicidad está jodido. Por eso decimos que es una enfermedad, ¿necesito simplemente sentirme bien porque jodí a otro? No, ya eso tiene vicios de esquizofrenia, de paranoia, de todos los males que el ser humano ha construido acabando con su entorno y con el resto de gente.

La propuesta del capital, la idea del desarrollo, es una idea de muerte, tiene de por medio la competencia, la eliminación del otro para poder ser exitoso. La idea nuestra es que no me puedo realizar si los otros no se realizan: si los demás no tienen avance en su bienestar yo no podría estar beneficiándome, porque no voy a tener una relación entre iguales con los demás. Entonces ahí está la apuesta, trascendiendo un poco a lo filosófico, está por esos lados. 